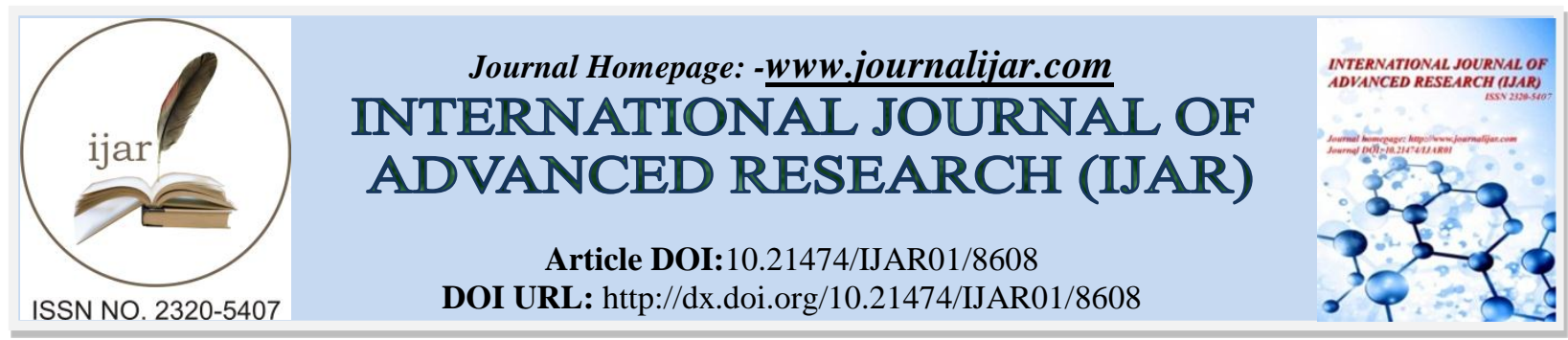

RESEARCH ARTICLE

\title{
PREDICTIVE FACTORS OF BIOLOGICAL ADRENAL INSUFFICIENCY AFTER A LONG-TERM GLUCOCORTICOID THERAPY.
}

Fatima Zahra El Bouazzaoui, Bahia Habra, Sana Rafi, Ghizlane El Mghari, Nawal El Ansari Department of Endocrinology, Diabetology and Metabolic Diseases, University Hospital of Marrakech, Marrakech, Morocco.

\section{Manuscript Info}

Manuscript History

Received: 04 January 2018

Final Accepted: 06 February 2019

Published: March 2019

Key words:-

Adrenal insufficiency, glucocorticoid use, stimulation test, adrenocorticotropic hormone $(\mathrm{ACTH})$.

\section{Abstract}

Purpose: The predictive factors of adrenal insufficiency after a prolonged, continuous course of corticosteroids is poorly documented. We evaluated it retrospectively in our department of endocrinology.

Methods: The patients were included between January 2015 to January 2017 and were administered a Synacthene ${ }^{\circledR} 250$ ug test (ST250) after substitution with hydrocortisone for at least 4 to 6 weeks. A nonresponsive test was defined by a cortisol increase below $21 \mathrm{ug} / \mathrm{dL}, 60$ min after stimulation. We studied the risk factors associated with biological adrenal insufficiency by SPSS analysis.

Results: sixty seven patients were included (mean age: $42 \pm 13,10$ years). Mean initial dose of corticosteroids was 41,95 $\pm 34,16 \mathrm{mg} / \mathrm{d}$. forty-three patients failed to respond to the ST250. The comparison between the responder group and the non-responder group at TS250 showed that the difference is significant for the basal cortisol level ( $\mathrm{p}=$ $0,016)$ and for the duration of the CTC $(\mathrm{p}=0.045)$.

Conclusion: Biological adrenal insufficiency is very common after a prolonged course of corticosteroids. Hence, clinicians should be vigilant for adrenal insufficiency at all degrees of glucocorticoid exposure.

Copy Right, IJAR, 2019,. All rights reserved.

\section{Introduction:-}

Corticosteroids are widely used in long-term treatment in many chronic diseases. They can lead to suppression of the hypothalamic-pituitary-adrenal (HPA) axis. The HPA-axis may remain suppressed following cessation of GC therapy, leaving the patient with adrenal insufficiency (AI). This deficiency is most often transitory, but can persist several months and cause non-specific symptoms such as fatigue and nausea whilst lack of the usual cortisol response to stress can lead to a potentially fatal adrenal crisis. AI has been a recognized side-effect of GC therapy since the early1950s [1-3]; Several studies in patients treated with CTC for rheumatoid arthritis, chronic inflammatory bowel disease (IBD) or chronic obstructive pulmonary disease have evaluated the frequency of this complication between 15 and 87\% [4-9]. The Synacthene ${ }^{\circledR} 250 \mu \mathrm{g}$ (TS250) test is the most widely used for screening biological IS because of its simplicity and excellent negative predictive value (97\%) [5]. The commonly accepted risk factors for IS are the duration of the CTC and the total dose received [6-8], The recovery time of the hypothalamic-pituitary axis after a long-term CTC is between one and 18 months [7]. We conducted a retrospective 
study to identify the predictive factors of biological IS in adult patients and to try to better characterize situations where the risk of developing this complication is important.

\section{Methods:-}

\section{Patients}

We conducted a retrospective study of 67 patients over a period of 2 years from January 2015 to January 2017. All patients are admitted to the hospital of the day in our service receiving a CTC equivalent to at least $5 \mathrm{mg} / \mathrm{d}$ of prednisone for more than three months. The synacthene 250 ug test was performed after substitution with hydrocortisone for at least 4 to 6 weeks.

\section{Data collection}

All patient files were reviewed, and information related to a potential adrenal insufficiency as well as demographics, glucocorticoid types and indications, the daily dose and duration were included in the analysis

\section{Realization of the test with Synacthène ${ }^{\circledR} 250 \mathrm{ug}$}

The test is performed in the morning on an empty stomach, 24 hours after the last dose of hydrocortisone. After taking the basal cortisol (synacthene ${ }^{\circledR}$ immediate) were injected. Cortisolemia was again measured at 60 minutes. TS250 was favored because because it's simple, sensitive, reproducible and without risk.

\section{Definition of test response}

The criterion for recovery or not of adrenal function (after discontinuation of synthetic corticosteroid and relay by the natural corticosteroid, hydrocortisone) was based on the response of cortisol $60 \mathrm{~min}$ after injection of synacthene 250 ug. For the definition of the test response, we did not take into account the basal cortisol level, even if it was less than $3 \mu \mathrm{g} / \mathrm{dL}$ [15]. The test was pathological for elevated cortisol less than $21 \mathrm{ug} / \mathrm{dL}$ in the 60th minute (nonresponder patients). For these patients another synacthene $250 \mathrm{~g}$ test was repeated after 3-6 months.

\section{Statistical analysis:-}

Statistical analysis was conducted using SPSS logiciel. The comparison between qualitative variables was made with the khi2 test. The comparison between quantitative variables was made with Student's t-test. Statistical significance was established with $\mathbf{P}$ less than 0.05 .

\section{Results:-}

Sixty seven patients were included in the study. There were 54 women and 13 men (sex ratio: 4.15) with an average age of $42 \pm 13,10$ years. The prednisone was the most used molecule in 51 cases (76\%) (Table 1). The mean initial dosage of CTC was $41,95 \pm 34,16 \mathrm{mg} / \mathrm{d}$. The average duration of the CTC was 89,97 $\pm 93,02$ months. The average duration between stopping corticosteroid therapy and performing the synacthene test was $6.53 \pm 4.11$ months. The mean baseline cortisol level was $98 \pm 70.30 \mu \mathrm{g} / 1$.

Table 1:-The main corticosteroid molecules used.

\begin{tabular}{|l|c|c|}
\hline Molecule used & Nombre of case & Pourcentage (\%) \\
\hline prednisone & 51 & 76 \\
prednisolone & 12 & 17,9 \\
dexamethasone & 2 & 2,98 \\
Betamethasone & 2 & 2,98 \\
\hline
\end{tabular}

Twenty Four (36\%) tests were normal, and forty-three (64\%) were non-responders (figure 1). The comparison between the responder group and the non-responder group at TS250 showed that the difference is significant for the basal cortisol level $(p=0,016)$ and for the duration of the CTC $(p=0.045)$. There was no difference between the responder group and the non-responder group for the initial daily dose of $\mathrm{GC}(\mathrm{p}=0.90)$ (table 2$)$. 


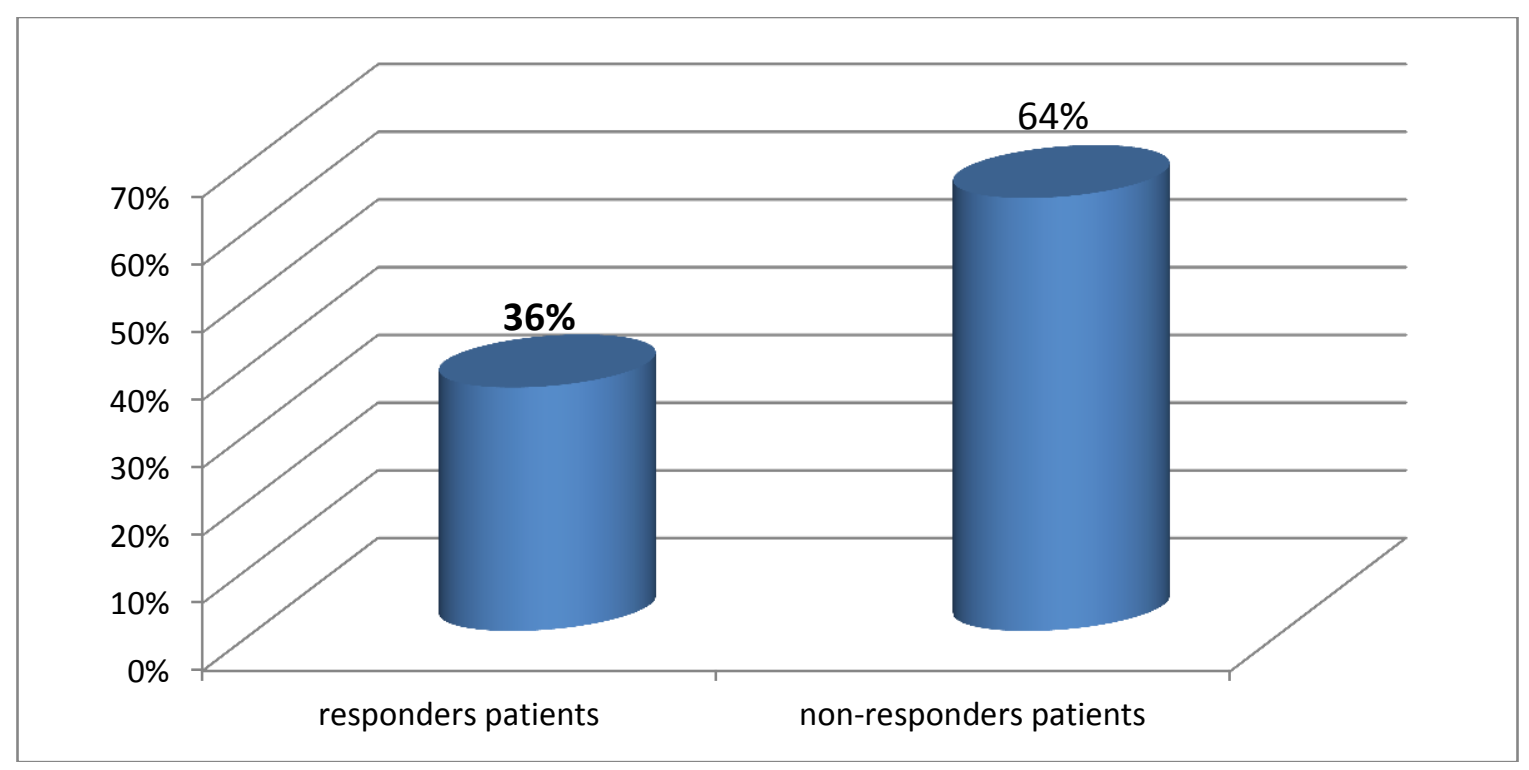

Figure 1:-Synacthene 250 ug test results

Table 2:-Evaluation of the relationship between the variables and the response to the synacthene test:

\begin{tabular}{|l|l|l|l|l|}
\hline & $\begin{array}{l}\text { Total } \\
(\mathrm{n}=67)\end{array}$ & $\begin{array}{l}\text { Responders } \\
\text { patients(n=24) }\end{array}$ & $\begin{array}{l}\text { Non-responders } \\
\text { Patients (n=43) }\end{array}$ & P \\
\hline Gender & 54 & 27 & 27 & 0.67 \\
$\begin{array}{l}\text { Women } \\
\text { Men }\end{array}$ & $42 \pm 13,10$ & 43.14 & 08 & 0.95 \\
Age (years) & $41,95 \pm 34,16$ & 40.83 & 42.87 & 0.90 \\
$\begin{array}{l}\text { Initial dose of } \\
\text { corticosteroid } \\
\text { (mg/d) }\end{array}$ & $89,97 \pm 93,02$ & 55.76 & 42.79 & 0.045 \\
$\begin{array}{l}\text { Duration of CTC } \\
\text { (months) }\end{array}$ & $98 \pm 70.30$ & 147.409 & 140.75 & 0.016 \\
$\begin{array}{l}\text { Baseline cortisol level } \\
\text { (ug/l) }\end{array}$ & $6.53 \pm 4.11$ & 7.14 & 75.357 & 0.44 \\
$\begin{array}{l}\text { The average duration } \\
\text { between stopping } \\
\text { corticosteroid therapy and } \\
\text { performing the synacthene } \\
\text { test (months) }\end{array}$ & 5.95 & \\
\hline
\end{tabular}

Of the 43 non-responder patients, nine were lost to follow-up. Of the 34 remaining patients, having had a second test in the third month, four were lost to follow-up after a new non-responder TS250, three had an indeterminate response at ninth month and 14 recovered normal response within 12 months of the first TS250. Of the 13 patients who still had a biologic AI at 12 months, five had after a new TS250 a definitive biological IS (followed by more than 36 months for the four patients). None of these five patients had metapyrone or insulin hypoglycemia tests. None of our patients had an IS crisis. 


\section{Discussion:-}

Glucocorticoids were introduced in the 1950s, and have been used for their anti-inflammatory and other pharmacological effects, and also as replacement therapy for adrenal insufficiency [1-3]. However, chronic glucocorticoid use may lead to suppression of the hypothalamic pituitary adrenal axis through negative feedback. This may lead to secondary adrenal insufficiency. Typically, the hypothalamic pituitary adrenal axis recovers after cessation of glucocorticoids, but the timing of recovery can be variable and can take more than 3 years [10 ].

Acute clinical IS after prolonged CTC is rare [11]. However, missing the diagnosis could lead to detrimental consequences. The administration of supraphysiologic doses of ACTH $(250 \mu \mathrm{g})$ is the standard challenge to test the adrenal responsiveness. This test has been widely used and several studies have reported an excellent agreement between peak cortisol concentrations obtained during the test and in the gold standard insulin tolerance test [12, 13].

Several studies have evaluated the risk factors of biological IS using this test in patients who have received longterm CTC. Pugnet et al [14] conducted a monocentric retrospective cohort study of 100 patients, A normal ST250 was negatively associated with a duration of corticosteroids therapy longer than 19.5 months $(\mathrm{OR}=0.38$ [0.15$0.94] ; \mathrm{p}=0.04)$ and positively with an age over 63.5 years $(\mathrm{OR}=2.5[1.1-6.4] ; \mathrm{p}=0.05)$. in Our study we have also demonstrate that the duration of CTC is risk factors of adrenal insufficiency $(p=0.045)$, but we have not proved a relationship between age and TS250 response. It is recognized that advanced age does not significantly affect the response of cortisol to corticotrophin injection [15]. Desarmé et al. did not identify a relationship between TS250 response and patient age [16].

An interesting result of our study is the identification a relationship between the basal cortisol level $(p=0,016)$ and the biological IS. Although this idea is widely accepted, we did not find a clinical study confirming this link through appropriate statistical tests.

In our patients the risk of definitive biological IS is real but difficult to quantify because of the large number of lost. Data from the literature indicate that recovery from normal cortisol secretion is the rule. It is obtained between five and 12 months after withdraw of a CTC greater than one year $[7,16,17]$. Beyond one year after stopping CTC, fewer than $5 \%$ of patients have biological IS [18]. The literature does not indicate follow-up beyond 18 months [16].

\section{Conclusion:-}

At the end of our study we found that the biological adrenal insufficiency is frequent after prolonged steroid treatment regardless of the treated disease. More than half of the patients in our study had asymptomatic biological IS at the time of withdrawal from their prolonged CTC. We identified as major predictors of biological IS are: duration of CTC and basal cortisol level.

\section{Conflicts of interest}

The authors declare no conflict of interest.

\section{References:-}

1. Sprague RG. et al. (1950) : Physiological effects of cortisone and pituitary adrenocorticotropic hormone (ACTH) in man. J Am Med Assoc, 144(16) :1341-7.

2. Fraser CG. et al. (1952): Adrenal atrophy and irreversible shock associated with cortisone therapy. J Am Med Assoc, 149(17) :1542-3.

3. Salassa RM. et al.(1953) : Postoperative adrenal cortical insufficiency: occurrence inpatients previously treated with cortisone. J Am Med Assoc, 152(16):1509-15.

4. Salvatori R. (2005) : Adrenal insufficiency .JAMA, 294(19) : 2481-8.

5. Chaieb L. et al. (1984) : Le test rapide à la 1-24 corticotrophine dans l'axe corticotrope. Presse Med, 13: 21837.

6. Sampson PA. et al. (1962) : Adrenal function in surgical patients after steroid therapy. Lancet, 1: 322-5.

7. Livanou T. et al. (1967): Recovery of hypothalamic-pituitary adrenocortical function after corticosteroid therapy. Lancet, 2(7521): 856-9.

8. Wood JB. et al. (1965) : rapid test of adrenocortical function. Lancet, 1(7379): 243-5.

9. Schalaghecke R. et al. (1992): The effect of longterm glucocorticoid therapy on pituitary-adrenal responses to exogenous corticotropin-releasing hormone. N Engl J Med, 326(4): 226-30. 
10. Rebecca M. et al. (2016): Systemic glucocorticoid therapy and adrenal insufficiency in adults: A systematic review Seminars in Arthritis and Rheumatism, 46 (1): 133-141.

11. Goichot B. et al. (2007) : Que reste-t-il de l'insuffisance surrénale post-corticothérapie ? Presse Med, 36(7) :1065-71.

12. Cunningham SK, et al. (1983): Normal cortisol response to corticotrophin in patients with secondary adrenal failure. Arch Intern Med,143(12): 2276-2279.

13. Oelkers W. (1998) : The role of high- and low-dose corticotrophin tests in the diagnosis of secondary adrenal insufficiency. Eur J Endocrinol, 139(6) : 567-570.

14. Pugneta, G. et al. (2010): Frequency and factors associated with biological adrenal insufficiency screened by the 250 ug corticotropin stimulation test after a prolonged course of systemic glucocorticoid therapy. A study of 100 patients. La Revue de médecine interne, 31: 332-336

15. Oliver C. et al. (1998) : Choice of diagnostic tests for adrenal cortex insufficiency. Ann Endocrinol, $59: 31-3$.

16. Desramé J. et al. (2002) : Assessment of hypothalamic-pituitary-adrenal axis function after corticosteroid therapy in inflammatory bowel disease. Am J Gastroenterol, 97:1785-91.

17. Aubert H, Kuhn JM. (1990) : Conséquences endocriniennes de la corticothérapie. Le sevrage d'une corticothérapie au long cours. Rev Prat, 40:

18. $544-8$.

19. Bertherat J (2002). Corticothérapie et fonction surrénalienne. Encycl Med Chir. 